\title{
Estado e economia na Coreia do Sul - do estado desenvolvimentista à crise asiática e à recuperação posterior
}

\author{
ALEXANDRE QUEIROZ GUIMARÃES*
}

The State and the economy in South Korea: from the developmentist state to the Asian crisis and later recovery. The article focuses on the institutions of South Korean capitalism and on the interactions between the state and the economy. The economic model in South Korea was characterized by a very interventionist state, which played a very active role in the process of industrialization. However, South Korea suffered a severe crisis in 1997, attributed by many authors to the distortions inherent to strong state intervention. The article shows that the crisis was a result of the combination between internal economic fragilities and a rapid process of financial deregulation, which undermined the state`s capacity of control. The crisis, nevertheless, does not disqualify the role of the national institutions in the very successful process of industrialization. Despite the reforms, the Korean capitalism conserves much of the previous model of business organization and industrial relations. The state continues strong and played active role in the process of economic reforms. There are, nevertheless, doubts about the impacts of the reforms and the new configuration of Korean capitalism. They will depend on the current transformations in world economy and in the East Asian countries.

Keywords: South Korea; developmental state; models of capitalism; Asian crisis; institutions and development.

JEL Classification: P16; P52; O53; N40; N45.

\section{INTRODUÇÃO}

Em 1997, uma grave crise abalou o leste da Ásia, atingindo principalmente a Coreia do Sul, Tailândia, Malásia e Indonésia. A crise, de magnitude comparável

\footnotetext{
* Ph.D. em Politics - Sheffield University, Professor do Mestrado em Administração Pública, Escola de Governo, Fundação João Pinheiro. E-mail: alexandre.queiroz@fjp.mg.gov.br. Submetido: Junho 2006; Aprovado: Novembro 2008.
} 
à Grande Depressão dos anos 1930, gerou impactos devastadores nos mercados de bens e de ativos: acentuada queda na produção, aumento do desemprego, agravamento dos problemas sociais, fuga de capitais e inúmeras falências. ${ }^{1}$ A catástrofe evidenciou algumas fragilidades internas a essas economias, assim como o potencial de instabilidade inerente à nova ordem internacional, marcada pelo fluxo descontrolado de recursos financeiros entre as fronteiras nacionais. A crise, por sua vez, desencadeou uma série de análises procurando associá-la às instituições do modelo asiático e aos problemas inerentes à forte intervenção do Estado na economia.

Este artigo aborda as particularidades institucionais do capitalismo asiático, destacando o impacto de algumas dessas instituições, entre elas um Estado fortemente intervencionista, sobre o desempenho econômico. Para isto, procura avaliar o papel desempenhado por essas instituições tanto no bem-sucedido processo de industrialização, como na forte crise de 1997. Para a consecução desse objetivo, faz-se necessário um enfoque que, sem desprezar as contribuições do Institucionalismo Econômico e das teorias da Escolha Pública, dê também atenção às especificidades institucionais dos países, relacionadas à organização do Estado, à organização dos grupos sociais e aos canais de interação entre o Estado e os grupos sociais (Hall, 1986).

A Ciência Econômica avançou significativamente no tratamento do Estado e nos impactos de sua intervenção na economia. Os anos 1970 foram marcados pela consolidação de teorias procurando entender os inúmeros casos de falhas do Estado verificados em experiências de desenvolvimento. Teorias e modelos centrados na captura de renda (rent seeking) e no risco moral (moral hazard) foram desenvolvidas para explicar as distorções e as dificuldades inerentes à excessiva intervenção do Estado na economia. No entanto, teorias que descrevem o Estado como um conjunto de agentes que maximizam seus interesses individuais são incapazes de explicar o Estado moderno e sua capacidade de produzir os bens públicos necessários ao funcionamento do mercado (Evans, 2004; Chang, 2006). Para este objetivo, o conceito weberiano de burocracia faz-se essencial. $\mathrm{O}$ artigo argumenta que teorias abstratas sobre o Estado devem ser combinadas com um enfoque histórico-institucional, mostrando que há diferenças entre os Estados e encontrando na capacidade do Estado (state capacity) uma variável central para explicar diferenças nas experiências de desenvolvimento econômico.

O foco na Coreia do Sul justifica-se por uma série de razões. Primeira, trata-se de uma referência permanente de um país que conseguiu romper o limiar do subdesenvolvimento. Segunda, trata-se de uma experiência em que a intervenção do Estado produziu resultados muito favoráveis e dificilmente replicáveis (World Bank, 1993). Terceira, a rápida mudança no curso dos eventos, passando de um rápido sucesso a uma crise devastadora e depois, a uma rápida recuperação, constitui um

\footnotetext{
${ }^{1} \mathrm{Na}$ Coreia do Sul, por exemplo, o produto caiu 7\% em 1998, houve forte aumento do desemprego e, entre 1997 e 1998, o número de pobres aumentou de 6 para 10 milhões (Eichengreen e Chung, 2004).
} 
objeto fértil para o estudo da Economia Política. Quarta, as semelhanças com o atual modelo chinês torna o entendimento do modelo coreano um tema bastante atual.

A segunda seção apresenta a gênese do Estado Desenvolvimentista, assim como alguns traços do modelo desenvolvimentista. A terceira seção enfatiza as dificuldades que já estavam presentes naquele arranjo, assim como os mecanismos que permitiram neutralizá-las. A quarta seção explora o papel da desregulamentação financeira, enquanto a quinta procura interpretar a crise. A sexta seção aborda a economia política da resposta à crise. A sétima aborda a relação da crise com as características institucionais do modelo coreano. A última seção avalia a economia coreana após as reformas, apontando resultados e desafios.

\section{O MODELO DESENVOLVIMENTISTA - GÊNESE E PRINCIPAIS CARACTERÍSTICAS}

A Coreia do Sul, à semelhança do Japão, construiu um modelo econômico marcado por forte intervenção estatal. Consolidou-se uma relação muito próxima entre o Estado e os grupos empresariais, em que o primeiro, por meio de incentivos e sanções, procurou moldar uma estrutura industrial robusta e competitiva. O controle do setor financeiro deu ao Estado forte capacidade de promover os setores considerados estratégicos. Uma alta capacidade de monitoramento, propiciada por uma burocracia capacitada, garantiu que os incentivos fossem acompanhados de aumento de produtividade, elevação na competitividade e capacidade de exportação (Amsden, 1989; World Bank, 1993). Durante as décadas de 1960 a 1980, a implantação desse modelo levou a um rápido e bem-sucedido processo de industrialização.

Um primeiro ponto é enfatizar a gênese do Estado desenvolvimentista, uma vez que os bons resultados estão relacionados às particularidades desse Estado. Embora a Coreia compartilhasse uma tradição confuciana que valorizava a burocracia, é fundamental destacar o impacto da colonização japonesa. Os japoneses destruíram o velho Estado patrimonialista, que apresentava fragilidade em relação aos grupos locais, e gestaram uma burocracia preparada e um Estado com alta capacidade tributária. Assim, a colonização japonesa produziu, junto com estímulos à atividade econômica, as precondições para a consolidação de um Estado desenvolvimentista no pós-guerra (Kohli, 2004).

Depois dos impactos da Segunda Guerra Mundial, da Guerra da Coreia e de um regime marcado, nos anos 1950, por corrupção e clientelismo, o golpe militar nos anos 1960 reformou o Estado e gerou as condições para a ação do Developmental State. Parte importante desse processo foi a criação do Economic Planning Board (EPB), agência dotada de autonomia, capacidade financeira e excelência burocrática para dirigir o processo de desenvolvimento. Todo o processo de reforma foi facilitado pela relativa fragilidade dos grupos econômicos. A classe agrária, relativamente fraca, em função da inexistência de commodities, foi adicionalmente enfraquecida pela reforma agrária realizada nos anos 1950. Por sua 
vez, a classe industrial era incipiente e tinha capacidade de resistência limitada (Haggard, 1990). ${ }^{2}$

As reformas ocorridas nos anos 1960, fundamentais para a reversão do curso da economia, foram favorecidas pelas pressões dos Estados Unidos, que se mostraram efetivas por causa da grande dependência da Coreia do Sul em relação à ajuda americana. Assim, apesar de tentar resistir, o governo do general Park cedeu, adotando medidas que incluíram a reforma no regime cambial e o combate à inflação. Essa foi a gênese do "Modelo de Promoção de Exportações", muito importante para que a forte intervenção do Estado não fosse acompanhada dos problemas que marcaram o processo de industrialização na América Latina (Haggard, 1990).

O empossado regime militar, seguindo o exemplo japonês, apostou na formação de grandes grupos empresariais, os chaebols, organizados em estrutura de conglomerado e com atuação em vários setores. Durante os anos 1960, os chaebols concentraram-se em produtos mais simples, assumindo a estrutura mais complexa e diversificada nos anos 1970, a partir de um ambicioso plano de investimentos nos setores da indústria pesada e química. Nesses anos, os chaebols cresceram a altas taxas e passaram a ocupar nichos nos setores de máquinas ferramentas, naval e automobilística. Nos anos 1980, o setor eletrônico ganhou importância (Woo-Cumings, 1999, p. 120).

Munidos de alta capacidade financeira, dadas suas ligações com o sistema financeiro estatal, esses conglomerados adquiriram maior capacidade de enfrentar a competição internacional e de avançar no aprendizado tecnológico. A estrutura em conglomerado propiciava vantagens de escopo e favorecia estratégias de longo prazo voltadas para a conquista de fatias do mercado. Assim, a estrutura agressiva e flexível dos chaebols desempenhou papel decisivo para o rápido processo de catch $u p$, tendo impacto decisivo na configuração do capitalismo coreano (Woo-Cumings, 1999). À semelhança do Japão, os chaebols propiciaram um processo de industrialização que prescindiu do capital estrangeiro, internalizando decisões centrais para o funcionamento da economia. ${ }^{3}$

A economia coreana passou a ser marcada, então, por um forte grau de concentração, em que os grandes grupos empresariais respondiam por expressiva parcela da produção e das vendas na economia. ${ }^{4}$ Outra característica dos chaebols foi seu alto grau de endividamento ${ }^{5}$ que, aliado a iniciativas do Estado para reduzir o

\footnotetext{
${ }^{2}$ A despeito disso, estes grupos tiveram influência nos anos 1950 e a Coreia do Sul apresentou muitos problemas familiares a um modelo de substituição de importações, incluindo produção industrial ineficiente, problemas crônicos no balanço de pagamentos e alta inflação.

${ }^{3}$ Sua presença foi, portanto, crucial para a capacidade do Estado de implementar programas bem-sucedidos de desenvolvimento tecnológico (Evans, 2004).

${ }^{4}$ Em 1989, os cinco maiores chaebols eram responsáveis por 9,2\% do valor adicionado na indústria. Em 1990, os 30 maiores grupos respondiam por 35\% do total das vendas industriais (Woo-Cumings, 1999, p. 122).

${ }^{5}$ A relação dívida-capital (debt to equity ratio) dos chaebols situou, nas três décadas anteriores à crise de 1997 , entre $300 \%$ e $400 \%$ (Woo-Cumings, 1999, p. 117).
} 
risco, favoreceu as altas taxas de investimento. $\mathrm{O}$ alto endividamento foi acompanhado de uma lucratividade inferior à média asiática, evidenciando a aposta em estratégias que, voltadas para a conquista de fatias do mercado, davam importância secundária à lucratividade. ${ }^{6}$

\section{LACUNAS E DIFICULDADES}

Existiam, no entanto, sérios limites à capacidade de regulação, uma vez que não havia agências regulatórias independentes e a relação Estado-empresas estava sujeita a regras informais e discricionárias. O sistema financeiro apresentava sérias fragilidades, dada a falta de uma estrutura de regulação adequada e a ausência de bons critérios de avaliação de risco. Como consequência, os bancos apresentavam baixa lucratividade, cobravam alto spread e acumulavam grande número de empréstimos podres (Chung, 2004). Outro agravante era a incapacidade de monitorar o destino das aplicações e de limitar as operações em ações e propriedades, usadas como colateral para a obtenção de novos empréstimos. Os bancos tendiam também a aceitar como aval a garantia pessoal dos donos dos chaebols, favorecendo a consolidação de um ambiente muito vulnerável à instabilidade financeira. Outra fonte de dificuldades encontrava-se na carência de bons mecanismos de governança corporativa. As empresas não adotavam bons critérios de contabilidade e não eram obrigadas a divulgar seus resultados, contribuindo para um quadro de falta de transparência (Joh, 2004).

Para Meredith Woo-Cumings (1999), essas dificuldades remontam a traços já apontados por Weber, que considerava o capitalismo asiático como pré-moderno, uma vez que faltavam regras formais-impessoais e um sistema de contabilidade empresarial avançado. Assim, o modelo econômico foi construído com vistas a suprir tais lacunas. A forte influência do Estado e a relação arbitrária entre governo e empresas constituíram-se em formas de substituir a falta de uma estrutura legal desenvolvida. ${ }^{7}$ Os grupos empresariais, por sua vez, organizaram-se por meio de estruturas familiares, que visavam substituir regras de contabilidade e de governança mais avançadas.

Segundo Woo-Cumings (1999), essas dificuldades estiveram presentes todo o tempo, embora tenham permanecido submersas em função do forte crescimento econômico e do alto grau de capacidade e coesão da burocracia, muito importante para garantir que a intervenção estatal produzisse bons resultados. Além disso, eram frequentes as iniciativas da burocracia para conviver com os desequilíbrios,

\footnotetext{
${ }^{6}$ A baixa lucratividade está fortemente relacionada ao elevado endividamento. Quando se consideram os lucros antes do pagamento de juros, a lucratividade não era mais baixa do que os padrões internacionais (Chang, 2006, cap. 6).

${ }^{7}$ Woo-Cumings (1999) fala de um modelo voltado para resultados em contraposição a um modelo fundado em regras formais claras; um modelo em que decretos administrativos e arbitrários substituíam normas legais transparentes.
} 
incluindo as tentativas de modernizar os mecanismos de avaliação de crédito e os procedimentos para tratar com os calotes. Por razões ligadas, entre outros aspectos, ao contexto externo e à maior autonomia dos Estados nacionais, esse foi um período muito profícuo do Developmental State, ajudando a entender sua contribuição para o bem-sucedido programa de industrialização.

Com o passar do tempo, porém, a necessidade de administrar as lacunas e deficiências levou à produção de um albatroz regulatório, que acarretou a acumulação de dificuldades (Woo-Cumings, 1999). A crescente intervenção tendia a intensificar tanto as divisões internas ao Estado como a pressão por parte dos grupos empresariais. Por sua vez, os políticos, que dependiam dos chaebols para financiamento eleitoral, tendiam a proteger os grupos empresariais e a boicotar as tentativas de reformas patrocinadas pelos burocratas. E enfim, os chaebols se fortaleceram e reduziram sua dependência em relação ao Estado.

Nos anos 1980, o retorno à democracia adicionou novas dificuldades. Durante o período autoritário, o presidente tinha mecanismos privilegiados de consulta e contava com mais instrumentos para impor suas decisões. A democracia, ao fortalecer os trabalhadores e outros segmentos, tornou inviável a manutenção de um modelo que se baseava na exclusão de muitos grupos. Além disso, a democracia deu aos chaebols canais adicionais para inserir reivindicações, além de aumentar a dependência financeira dos políticos em relação aos empresários. Assim, se, de um lado, a democracia favoreceu a canalização de vozes descontentes com os privilégios recebidos pelos chaebols, de outro, fortaleceu esses grupos e reduziu a capacidade da burocracia de impor as reformas necessárias (Chang, 2006, cap.6).

Não obstante, os burocratas procuraram avançar iniciativas visando reduzir o endividamento e o grau de diversificação dos chaebols e equacionar o excesso de capacidade presente em vários setores (Hagard, 2000, pp. 36-37, 42). As tentativas chocavam-se no entanto com a alta capacidade de resistência dos chaebols. A infante democracia coreana era incapaz de formar uma coalizão para reformar o modelo (Lee et al., 2005). Além disso, a privatização do sistema financeiro e as oportunidades abertas pela desregulamentação financeira deram aos chaebols mais recursos para resistir às ofensivas. Como aponta Woo-Cumings (1999), foi necessária a deflagração de uma grave crise, além do aval do FMI, para o governo aprovar as reformas capazes de reduzir algumas distorções que estavam na raiz das dificuldades.

A crise de 1997 está, portanto, em parte ligada a essas dificuldades internas ao modelo, especificamente às lacunas no aparato de regulação, e às dificuldade em reformar os chaebols e modificar suas relações com o sistema financeiro. Outras crises de menor magnitude, apontando excesso de capacidade na indústria, fragilidades no sistema financeiro e a existência de bolhas especulativas, ocorreram em anos anteriores (Woo-Cumings, 1999). A peculiaridade da crise de 1997 foi sua amplitude, favorecida pela rápida desregulamentação financeira, pela fragilidade no balanço de pagamentos e pelo fluxo de capital especulativo. 


\section{DESREGULAMENTAÇÃO, FLUXO DE CAPITAIS E CRISE}

Um componente central da crise de 1997 foi o processo de desregulamentação financeira. Em 1991, pressionado pelos Estados Unidos, mas também pelos chaebols, o governo licenciou a atuação de bancos de investimento e eliminou a restrição para a emissão de commercial papers, favorecendo o endividamento de curto prazo em moeda estrangeira (Haggard, 2000, p. 37). Posteriormente, medidas foram adotadas na direção de uma maior liberalização da conta de capitais. Estas reformas deram aos chaebols, que controlavam instituições financeiras não bancárias, grande oportunidade de lucros. A pressão dos chaebols ajuda a explicar a forma assumida pelo processo de liberalização, centrado em facilitar o acesso ao crédito internacional, mas restringindo a participação estrangeira nos mercados de títulos e ações.

Essas reformas foram acompanhadas pelo desmonte do Developmental State, que culminou, em 1993, com o fechamento do EPB, parte da estratégia coreana de se tornar membro da Organização para Cooperação e Desenvolvimento Econômico (OCDE) (Cumings, 1999, p. 26). As consequências desse rápido processo de desregulamentação foram: de um lado, aumentaram-se os canais para a mobilização de recursos por parte dos investidores; de outro, reduziram-se os mecanismos de controle e regulação disponíveis para o governo. Aumentava-se, fortemente, o risco de crescimento da especulação, principalmente tendo-se em conta a regulação muito precária e os mecanismos débeis de governança empresarial.

Vale, pois, enfatizar o impacto desse processo de liberalização nas dificuldades que o modelo passou a enfrentar. $\mathrm{O}$ modelo desenvolvimentista coreano, assim como o japonês, dependia de um forte arranjo interno de regulação, indispensável para neutralizar as fontes potenciais de instabilidade presentes no sistema financeiro e na organização dos grupos empresariais. $\mathrm{O}$ insulamento do modelo e sua capacidade de regulação ficaram fortemente comprometidos com as medidas que visavam desregulamentar o sistema financeiro e reduzir a intervenção estatal. O novo quadro exigia reformas rápidas, mas essas eram bloqueadas pelos chaebols, assim como pelas grandes dificuldades do sistema financeiro.

Assim, as dificuldades internas ao modelo devem ser combinadas com o vetor relacionado à desregulamentação financeira. Os anos 1990 foram marcados pelo rápido crescimento dos fundos de pensão americanos, que, mobilizando grande quantidade de recursos e engajados em acirrada competição, direcionaram-se fortemente para os países do Leste e Sudeste Asiático. ${ }^{8}$ Eram recursos privados, que superavam em muitas vezes as reservas nacionais. Uma dificuldade adicional é que a região enfrentava dificuldades no balanço de pagamentos, resultado da valorização do dólar, moeda à qual as moedas locais estavam atreladas, da crise japonesa e da desvalorização da moeda chinesa. A má performance ex-

\footnotetext{
${ }^{8}$ Problemas locais, como má regulação e fragilidade do sistema financeiro, foram deixados em segundo plano.
} 
portadora foi acompanhada pelo crescimento do endividamento externo, predominantemente de curto prazo.

\section{INTERPRETANDO A CRISE}

Apesar de tentativas nessa direção (Eichengreen e Chung, 2004; Krugman, 1998), a crise asiática não pode ser deduzida das pretensas contradições do modelo asiático. Aspectos internos ao modelo agravaram as dificuldades, mas são incapazes de explicar a eclosão e a magnitude dos eventos. O entendimento da crise requer, essencialmente, o reconhecimento do potencial especulativo e de instabilidade inerente aos mercados financeiros (Minsky, 1986). Em períodos de otimismo, surgem inovações financeiras que acarretam fortes oportunidades de lucro. Instituições financeiras captam recursos de curto prazo que se destinam a aplicações no mercado de ativos e a financiamentos a longo prazo. Apesar de certa cautela inicial, as fortes oportunidades de lucro levam as instituições a engajarem, crescentemente, em posições especulativas. Nesse momento de otimismo, os investidores não percebem os riscos relacionados a uma súbita mudança de humor dos mercados. ${ }^{9}$

A reversão se deflagra com a indicação de que o valor esperado dos investimentos não se realizará, seja porque a demanda não cresce como esperado, porque os custos aumentam ou porque as expectativas de alta são revertidas. A partir de então, os ativos perdem o valor e as firmas, fortemente endividadas, perdem capacidade de se financiar. Passam a vender desesperadamente os ativos, que perdem drasticamente o valor. Os bancos, por sua vez, recolhem o financiamento, ampliando as dificuldades de liquidez e/ou solvência dos agentes financeiros e das empresas.

Arestis e Glickman (2002) mostram que a teoria de Minsky é a que melhor descreve os eventos da crise asiática. A abertura financeira permitiu a forte captação de recursos de curto prazo em moeda estrangeira. Fundos e bancos internacionais foram também fortemente atraídos. O otimismo e a alta perspectiva de lucro inibiram o comportamento conservador. Como consequência, os agentes foram se engajando em posições especulativas, contribuindo para a formação da bolha no mercado de ativos. ${ }^{10}$ Em 1997, no entanto, o otimismo foi revertido, dadas as percepções de fragilidades das economias e os retornos não esperados das aplicações. Era o sinal para a explosão da bolha. Em tal situação, os financiadores recolheram seus recursos e as instituições encontraram dificuldades para se financiarem. Os

\footnotetext{
${ }^{9}$ Minsky (1986) chama de situação especulativa aquela em que os juros devidos pelas empresas excedem as receitas previstas na operação de negócios. Inicialmente, o comportamento especulativo é exceção, mas o otimismo tende a reforçá-lo. Além disso, mesmo firmas que se consideram em posição mais segura (hedge) podem se tornar especulativas, dado que ficam vulneráveis a mudanças nos juros, no câmbio e em outras variáveis.

${ }^{10}$ Segundo Arestis e Glickman (2002), baseando em estudo econométrico e comparativo, a chance de um país ser envolvido pela crise esteve positivamente correlacionada ao grau de abertura financeira e negativamente correlacionada à capacidade de regulação.
} 
investidores, por sua vez, repatriaram rapidamente seus investimentos, temendo, mas também provocando, a desvalorização da moeda.

A eclosão da crise deveu-se também à fragilidade apresentada no balanço de pagamentos, resultado de estratégias coniventes com a alta captação de poupança externa (Bresser-Pereira, 2001a, 2001b; Gonzalez, 2007). O influxo de capital de curto prazo, acompanhado de déficits em transações correntes, aumentou o grau de fragilidade dessas economias, a despeito de outros bons fundamentos econômicos. Em tal situação de endividamento, o aumento das reservas fornece um sinal ilusório, dado que os déficits em transações correntes e o aumento da relação dívida/exportações contribuem para aumentar a fragilidade da posição do Banco Central.

Inicialmente, houve forte captação de recursos externos, favorecida pelo atrelamento da moeda ao dólar e pelas altas perspectivas de lucros. O aumento das reservas fortaleceu passageiramente o otimismo, apesar dos déficits em transações correntes introduzirem novo elemento de fragilidade. A percepção de aumento dos riscos levou os credores a adotar posição mais cautelosa, até que, em estágio ulterior, reduziram a posição em moeda nacional e passaram a retirar recursos do país. A percepção desse comportamento levou os investidores a desfazer operações em moeda estrangeira, enquanto os investidores estrangeiros repatriavam seus investimentos. Como consequência, a forte demanda por moeda estrangeira tornou o Banco Central insolvente, forçando-o a desvalorizar a moeda e agravando as dificuldades dos agentes endividados em moeda estrangeira.

Esse ciclo descreve bem os eventos de 1997. Bancos estrangeiros, percebendo fragilidades na economia tailandesa, passaram a retirar rapidamente recursos do país. A perspectiva cada vez mais eminente de o governo não manter a paridade do baht com o dólar desencadeou sucessivas fugas de recursos, configurando uma profecia autorrealizável. Algo similar ocorreu nos países vizinhos, motivado pela percepção de que as fragilidades eram compartilhadas. A baixa transparência e os fortes problemas de regulação favoreceram a volatilidade e o potencial explosivo da crise. ${ }^{11}$ O movimento provocou quebra dos mercados imobiliário e de ações e forte queima no valor dos ativos. A necessidade de elevar os juros, na tentativa de proteger a moeda, agravou ainda mais os problemas das empresas, fortemente endividadas. ${ }^{12}$ A grande fragilidade do setor financeiro contribuiu para o alastramento do problema. Por sua vez, os países da região que ficaram imunes à crise confirmam a relevância das variáveis supradestacadas. Taiwan, embora compartilhando a relação próxima entre o Estado e as empresas, tinha reservas mais sólidas, não havia sofri-

\footnotetext{
${ }^{11}$ Assim, enquanto em 1996 US\$ 96 bilhões em aplicações financeiras haviam entrado na Coreia do Sul, Tailândia, Malásia, Indonésia e Singapura, no final de 1997 US\$ 199 bilhões deixaram estes países (Haggard, 2000).

${ }^{12} \mathrm{Na}$ Coreia do Sul, $49 \%$ das empresas ficaram ilíquidas e $40 \%$ tecnicamente insolventes (WooCumings, 1999, pp. 123-124). Cinco grandes grupos, com força de trabalho superior a 100 mil empregados, quebraram devido à incapacidade de honrar suas dívidas.
} 
do forte endividamento externo e havia adotado um programa bem mais cauteloso de desregulamentação financeira.

A importância do argumento de Minsky é enfatizar o potencial de instabilidade inerente aos mercados financeiros, resultado de um comportamento centrado em convenções e na tentativa de antecipar as decisões dos demais agentes. Este comportamento tende a levar a posições arriscadas, não pela crença de que os agentes serão socorridos, como argumenta Krugman (1998), mas pelas altas oportunidades de lucro e pela dificuldade, durante o otimismo, de perceber o risco de uma mudança de curso. $\mathrm{O}$ argumento de Minsky constitui uma excelente crítica aos argumentos que associam a crise a fenômenos como risco moral, cronismo e à "excessiva” intervenção do Estado.

\section{A ECONOMIA POLÍTICA DA RESPOSTA À CRISE}

Um ponto importante acerca da resposta à crise foi que os principais países atingidos procuraram avançar reformas na direção de fortalecer o sistema financeiro, criar agências regulatórias mais independentes, gerar maior transparência e amenizar a relação arbitrária entre o governo e os grupos empresariais. A pressão dos Estados Unidos e do FMI foi decisiva para o curso das reformas. Os Estados Unidos já vinham, desde o início da década, engajando em iniciativas que visavam à abertura dos mercados do Leste Asiático aos seus produtos e investimentos. Com a crise, viram a oportunidade de desmontar muitas das instituições do modelo asiático, sob o protesto de empresários e burocratas que reconheciam a importância de certos mecanismos para o bem-sucedido processo de industrialização (Cumings, 1999). Nesse processo, a grande dependência dos países em relação aos recursos deu ao FMI grande capacidade de pressionar pelas reformas. ${ }^{13}$

Avaliando as respostas à crise, uma variável central é a relação entre os empresários e o Estado. Haggard (2000) concluiu que os governos autoritários não estavam menos vulneráveis às pressões do setor privado, ponto muito bem ilustrado pela Indonésia. Uma vantagem dos países democráticos foi contar com os mecanismos de autocorreção propiciados pela democracia, dado que a troca de governo tende a gerar apoio político para enfrentar as dificuldades. Comparando os governos democráticos da Tailândia e da Coreia do Sul, nota-se que a Coreia beneficiou-se de uma estrutura institucional que favorecia a autonomia do Executivo, enquanto a Tailândia sofreu as consequências de um sistema partidário muito fragmentado e do vínculo muito próximo entre alguns grupos empresariais e o governo.

A resposta coreana à crise foi rápida e efetiva. Seu sucesso deveu-se à criação da Financial Supervisory Commission (FSC), uma agência criada com grande au-

\footnotetext{
${ }^{13}$ A esse respeito, vale também dizer que o governo coreano soube muito bem usar a intervenção do FMI, atribuindo ao órgão a responsabilidade por medidas cujos custos e resistência política eram muito altos.
} 
tonomia e capacidade para implementar as reformas. A direção e o sucesso das reformas foram também favorecidos pelos atributos do presidente eleito em 1997, Kim Dae Jung, um ex-perseguido político que acreditava que as ligações privilegiadas entre os chaebols e o governo eram resquícios do regime autoritário. Kim Dae Jung tinha laços com os trabalhadores e com os grupos populares e procurou utilizá-los para reforçar o apoio político em favor das reformas. Fez concessões aos trabalhadores, incluindo um lugar na mesa de negociações, a criação do seguro desemprego e melhorias na rede de seguridade social. As concessões, bastante significativas, foram usadas como contrapartida para a realização de reformas difíceis, que incluíam grande número de demissões (Haggard, 2000). ${ }^{14}$

Kim Dae Jung explorou a impopularidade dos chaebols, considerados responsáveis pela crise, além de suas dificuldades financeiras, para fazer avançar as reformas. Convocou reuniões com os líderes dos maiores grupos e negociou um processo de reestruturação empresarial. Procurou introduzir mudanças na governança corporativa, reduzir a diversificação dos chaebols, eliminar as práticas de subsídios cruzados e concentrar os grupos nos setores em que tinham maior especialidade. Houve resistência por parte dos grandes grupos, mas as dificuldades financeiras levaram-nos a recuar e a fazer concessões. Em junho de 1998, a FSC vetou o acesso ao crédito a 55 empresas, incluindo 20 subsidiárias dos cinco maiores grupos (Haggard, 2000, pp. 102, 155). Ao mesmo tempo, disponibilizava amplas linhas de crédito para facilitar a reestruturação. ${ }^{15}$

Foi também atribuição da FSC decidir quais bancos eram viáveis e quais o governo deveria deixar quebrar. Além disso, a FSC impôs padrões internacionais de regulação sobre o sistema financeiro, incluindo critérios de adequação de capital e de classificação dos empréstimos e a exigência de maior diversificação das aplicações (Haggard, 2000, p. 142). Outro componente da reforma foi a eliminação de grande parte das restrições para a entrada de capital estrangeiro, medida que visava facilitar as fusões e aquisições e reduzir a diversificação dos chaebols.

As reformas avançaram bastante, tendo produzido agências regulatórias mais independentes, melhor regulação financeira e novas regras de governança corporativa. Melhores procedimentos foram introduzidos para o gerenciamento do endividamento das empresas e o número de empréstimos podres reduziu-se de $8,3 \%$ em 1999 para 1,9\% em 2002. A relação debt-equity também caiu consideravelmente. No que tange à governança corporativa, regras foram adotadas para aumentar a participação dos acionistas minoritários e aumentar a responsabilidade dos acionistas controladores. Foram também fortalecidos os padrões de auditoria

\footnotetext{
${ }^{14}$ Como apontam Lee et al. (2005), Kim Dae Jung era considerado dissociado das dificuldades anteriores, o que favoreceu sua capacidade de realizar as reformas. Apesar dos fortes custos sociais, sua aprovação aumentou, atingindo $70 \%$ em abril de 1998 .

${ }^{15}$ Como exemplo, a FSC vetou o acesso ao crédito à LG Semicon como forma de induzir sua fusão com a Hyundai eletrônica e formar um campeão nacional (Weiss, 2003, p. 252). Mais tarde, o grupo Daewoo foi fechado, com forte impacto econômico e social, levando o governo a adotar uma posição mais branda em relação a outros grupos em dificuldades (Chung, 2004, p. 37).
} 
e de contabilidade, com a exigência de auditores externos e da emissão de relatórios periódicos (Joh, 2004, p. 213). ${ }^{16}$ Ao lado de algumas reformas positivas, no entanto, contrapõe-se o impacto de mudanças que teriam reduzido a capacidade de investimento e a versatilidade dos grupos empresariais (Chang, 2006; Lee et alii, 2005).

Observando o processo de reforma, vale destacar a grande autonomia e capacidade de ação do Estado. Dado o enfraquecimento dos chaebols e dos trabalhadores, os burocratas preencheram o vácuo e assumiram a condução das reformas. Assim como no passado, os políticos reinavam, mas os burocratas governavam. Os bancos foram recapitalizados e o Estado chegou a controlar $90 \%$ das ações dos cinco maiores bancos, garantindo forte influência na alocação dos recursos financeiros e na promoção das direções desejadas (Lee et al., 2005). ${ }^{17}$

Weiss (2003) destaca que a ação do FSC, na direção de reestruturar os chaebols e de prepará-los para a competição internacional, pautou-se nos três princípios que caracterizaram, algumas décadas atrás, a ação do Developmental State: a força da agência-piloto; a relação institucionalizada entre burocracia e empresários; e a definição de metas para reformar a economia. Os burocratas tiveram grande discrição, indicando os setores em que os chaebols deveriam atuar e pressionando por fusões com o objetivo de ampliar as vantagens de escala e reduzir o risco de acumulação de excesso de capacidade. A FSC, à semelhança do antigo EPB, usou a combinação de incentivos e sanções para atingir seus objetivos. Os chaebols que se recusaram a adotar as mudanças tiveram o acesso ao crédito negado e foram submetidos a um controle mais estrito sobre o pagamento de impostos.

\section{A CRISE, AS INSTITUIÇÕES E OS CRÍTICOS DO MODELO ASIÁTICO}

A crise de 1997 está relacionada a um forte processo especulativo. Seu timing e sua magnitude relacionam-se ao rápido processo de liberalização financeira, acompanhado pela eliminação de uma estrutura prévia de regulação antes que uma nova estrutura estivesse estabelecida. Ao procurar interpretá-la, os críticos do modelo desenvolvimentista acertam ao apontar o papel das fragilidades internas, principalmente as lacunas do aparato de regulação e a pouca transparência das empresas. Entretanto, falham ao não destacar a contribuição do vetor ligado à desregulamentação financeira, assim como o potencial de instabilidade implícito nos mercados. Em outras palavras, estes críticos falham fortemente ao procurar

\footnotetext{
${ }^{16}$ Segundo Eichengreen e Chung (2004), ainda existe, no entanto, grande lacuna em termos de transparência, faltando mecanismos que favoreçam a expulsão das firmas ineficientes. Os autores criticam o padrão de ação da FSC, enfatizando que não cabe ao Estado decidir quais firmas devem atuar em quais setores.

${ }^{17}$ Segundo Lee et al. (2005), as instituições informais ajudam a explicar a persistência da influência estatal. Os coreanos, seguindo a tradição confuciana, acreditam que o governo deve ter papel ativo na promoção do bem público.
} 
atribuir ao Estado e às instituições asiáticas parte da responsabilidade que deve ser atribuída à instabilidade endêmica dos mercados, agravada pelo acelerado processo de desregulamentação financeira.

Está implícita, em variantes desse tipo de interpretação, uma visão bastante negativa do modelo desenvolvimentista asiático, bem ilustrada pela ênfase em explicar o processo e o sucesso da industrialização a despeito - e não por causa - das instituições do modelo (Eichengreen e Chung, 2004). Da mesma forma, está presente a ideia da intervenção estatal como prejudicial e fadada ao fracasso, bem como a indicação da possibilidade de apenas um modelo bem-sucedido de capitalismo. ${ }^{18}$ Tais críticas incorporam um viés decorrente da aplicação direta, sem as devidas mediações, de teorias econômicas abstratas para interpretar experiências concretas de desenvolvimento.

O ponto é bem exemplificado pela incapacidade de apreender o papel do Estado desenvolvimentista na industrialização asiática, explicada pelas tentativas de interpretar o Estado a partir das teorias de "Escolha Pública" e "Captura de Renda", desconsiderando as particularidades institucionais que explicam a emergência de um Estado com grande capacidade para coordenar o processo de desenvolvimento (Evans, 2004; World Bank, 1993). O Estado coreano desempenhou importantes funções, que incluíram a alocação de crédito subsidiado, a adoção de procedimentos para a redução do risco de investimentos estratégicos, a participação na negociação para a importação de tecnologia e o estímulo ao desenvolvimento tecnológico. A política industrial beneficiou-se da capacidade de conciliar proteção e estímulos com a pressão por aumento de exportações, permitindo a conquista de mercados externos e a expansão da escala (Chang, 2006). Seu sucesso está relacionado a intervenções que buscavam complementar, ao invés de substituir, a ação do setor privado.

O êxito coreano não pode, portanto, ser explicado meramente pelas inúmeras oportunidades de investimento e pelas possibilidades de catch up presentes nas primeiras fases de industrialização, como sugerido por Eichengreen e Chung (2004). Tampouco pode ser interpretado como resultado de altas taxas de poupança e de investimento em uma economia caracterizada por baixa produtividade, como proposto pela teoria dos "tigres de papel". As instituições coreanas, incluindo os grupos empresariais e o Estado, influenciaram positivamente as altas taxas de investimento, o bem-sucedido processo de avanço tecnológico e a captura de mercados internacionais em setores de ponta. Nesse processo, vários são os exemplos de políticas bem-sucedidas de fomento aos setores industriais (Amsden, 1989; Evans, 2004). ${ }^{19}$

\footnotetext{
${ }^{18} \mathrm{Na}$ mesma direção está presente a ideia de Adam Smith de que as forças de mercado têm grande potencial para promover o progresso econômico, que tende a ocorrer mesmo quando a "ordem natural das coisas" é prejudicada pela loucura dos governantes.

${ }^{19}$ A política de informática adotada nos anos 1980 é um excelente exemplo. A ação foi centrada na redução do risco e na adoção de uma política de compras nos estágios iniciais e de medidas visando complementar o esforço de inovação do setor privado.
} 
$\mathrm{Na}$ mesma direção, é equivocado interpretar a crise como resultado do "risco moral" ou do "dilema principal - agente". Em primeiro lugar, a intervenção do Estado não era, em regra, acompanhada de indulgência. Firmas em dificuldades eram reestruturadas e o mal gerenciamento era rigorosamente punido (Chang, 2006, cap. 6). Similarmente, não é possível interpretar a dinâmica dos grupos empresariais como resultado de ações dos controladores à custa dos demais acionistas. Há fortes evidências de eficiência na ação dos grupos empresariais, assim como de efeitos positivos da estrutura em forma de conglomerado. ${ }^{20}$ Houve, certamente, dificuldades advindas do endividamento excessivo e da falta de transparência dos chaebols, da mesma forma que sua força excessiva bloqueou a realização de reformas necessárias. No entanto, não se trata de "captura de renda, "risco moral" ou "dilema principal-agente". O ponto correlato a se destacar é que o diagnóstico oficial da crise teve consequências, sendo utilizado para adotar reformas na direção de reestruturar os grupos empresariais, comprometendo também traços positivos do modelo anterior (Chang, 2006).

\section{LIÇÕES, DESAFIOS E CONCLUSÕES}

Uma importante lição da crise de 1997, bastante relevante para o caso chinês, consistiu em evidenciar que as normas legais importam. Durante algum tempo, acreditou-se que mecanismos informais poderiam ser substitutos razoáveis. Os eventos demonstraram a importância das regras formais, incluindo a regulação do setor financeiro e as regras de governança corporativa. Melhores regras teriam aumentado a transparência e reduzido a fragilidade do sistema econômico. Os avanços feitos nessa direção são inegavelmente um legado positivo da crise de 1997.

A Coreia do Sul mostrou grande capacidade e agilidade na adoção das reformas, o que explica a rapidez da recuperação econômica. Tal sucesso dependeu de uma estrutura institucional que dava grande força ao Executivo e da capacidade de ação da burocracia, fortalecida pelo enfraquecimento dos chaebols. O êxito foi também criticamente afetado pelas características do presidente eleito, dissociado das dificuldades anteriores e detentor de apoio político e legitimidade para adotar as medidas necessárias.

As reformas trouxeram muitos avanços, incluindo o saneamento do setor financeiro e a redução no grau de endividamento dos chaebols. Houve também avanços nos padrões de contabilidade e auditoria e a adoção de práticas que tornaram as empresas mais transparentes. Os grupos empresariais foram reestruturados, tornando-se menos diversificados, as garantias cruzadas foram eliminadas e algumas subsidiárias insolventes foram fechadas. Para os 30 maiores chaebols, a

\footnotetext{
${ }^{20}$ Existia uma ética diferente na ação dos gerentes, ligada à visão do grupo empresarial como uma grande família. É simplista interpretar suas ações como decisões utilitárias visando ao ganho pessoal à custa dos outros membros.
} 
lucratividade média, que se situava em $0,8 \%$ em 1998, aumentou para 3,48\% em 2002 (Lee et al., 2005).

No entanto, a crise trouxe também dificuldades para os grupos empresariais, ameaçando traços institucionais que haviam contribuído para o sucesso anterior. Antes da crise, o trabalho em equipe era valorizado, os salários eram proporcionais ao tempo de serviço e o chaebol era responsável pelas funções de welfare. A crise desestruturou essas relações, tornando os trabalhadores redundantes e levando os controladores a pressionar por demissões, iniciativa enfrentada com resistência pelos trabalhadores. ${ }^{21} \mathrm{~A}$ tentativa de introduzir um mercado de trabalho mais flexível chocou-se também com a falta de instituições de treinamento e de agências de reinserção dos trabalhadores (Lee et al., 2005).

Houve forte queda do investimento. Depois de se situar em patamares de 37\% do PIB entre 1993 a 1996, o investimento caiu para 27\% do PIB no período 1999 a 2002 (Lee et al., 2005)..22 Segundo Chang (2006, pp. 300-303), o período 1999 a 2001, quando comparado com o período anterior à crise, foi também marcado pelo menor crescimento das vendas e pela redução tanto da taxa de lucro operacional como da taxa de lucro real da economia. Segundo Lee et al. (2005), houve também sinais de redução no ritmo de mudança tecnológica, de maior atraso relativo de muitos setores em relação aos líderes internacionais e de menor capacidade de geração de empregos.

Chang (2006) critica a forma rígida como foi feito o processo de reestruturação. A imposição de um critério rígido da relação debt-equity teria amarrado as empresas, enquanto a forma rígida como se procurou introduzir os padrões internacionais de adequação de capital implicou a incapacidade dos bancos em socorrer as firmas necessitadas, agindo de forma pró-cíclica e condenando mesmo empresas viáveis. Além disso, Chang critica as reformas voltadas a eliminar os subsídios cruzados dentro dos chaebols, dado que comprometeram sua versatilidade e a capacidade de conquista de outros mercados.

Portanto, Chang (2006, p. 304) argumenta que as reformas afetaram também o lado bom dos chaebols, reduzindo sua capacidade de investimento e de penetração em outros setores. As reformas são sobretudo criticadas pela falta de ênfase no crescimento de longo prazo e por uma preocupação excessiva com a lucratividade de curto prazo, indicação de maior sensibilidade aos interesses financeiros do que aos interesses da indústria. Segundo Chang (2006), menos do que a importação de práticas do modelo anglo-saxão, a Coreia necessita de uma nova etapa de catch $u p$, aproveitando os pontos positivos do modelo desenvolvimentista e adaptando-os aos novos desafios.

\footnotetext{
${ }^{21}$ Como consequência, as relações de trabalho dentro dos chaebols tornaram-se fortemente rígidas, dificultando a reestruturação.

${ }^{22}$ Segundo os dados da Penn World Table (http://pwt.econ.upenn.edu), a parcela do investimento no produto interno bruto real caiu de 40,5\% e 42,3\% em 1992 e 1994 para 33,2\% e 33,1\% em 2003 e 2004. A despeito dos excessos em anos anteriores, acredita-se que a redução foi longe demais.
} 
Em síntese, apesar de melhoras visíveis em certos indicadores, há dúvidas quanto ao impacto sobre o desempenho da economia. Enquanto alguns autores destacam que as reformas falharam em não terem avançado suficientemente (Chung, 2004), outros questionam a adequação das mesmas às instituições coreanas, assim como seus impactos no investimento e em outras variáveis (Chang, 2006; Lee et Al., 2005). O fato é que, apesar das mudanças, há ainda fortes elementos de conservação, atestados pelo alto grau de discrição e intervenção do Estado, pelas características dos grupos empresariais ${ }^{23}$ e pela persistência das relações de trabalho.

A economia coreana enfrenta hoje fortes desafios, diretamente relacionados à nova configuração da economia asiática. Entre 1998 e 2005, o Leste Asiático cresceu $9 \%$ ao ano, havendo grande crescimento do comércio intrarregional. Nos anos 1980, firmas coreanas investiram pesadamente na China, que hoje é também o principal destino das exportações coreanas. No entanto, o avanço chinês nos setores de eletrônica e tecnologia da informação transformou-se em forte ameaça. A economia coreana estaria portanto espremida entre o tecnologicamente avançado Japão e a economia de baixos custos da China. O governo coreano vem respondendo na direção de uma maior abertura ao capital estrangeiro ${ }^{24}$ e da assinatura de tratados de livre-comércio, incluindo um amplo tratado com os Estados Unidos. Essas medidas podem ser interpretadas como apostas para avançar em direção à uma economia do conhecimento, considerada vital para enfrentar a competição chinesa.

Um grande desafio diz respeito à geração de empregos, dado que as indústrias trabalho intensivas estão em declínio e os setores mais dinâmicos têm reduzido a absorção de emprego. Uma alternativa é o setor serviços, que encontra-se ainda muito atrasado. Outro imperativo é a melhoria da capacidade tecnológica e o fortalecimento da pesquisa básica, uma vez que o sistema de inovação é muito viesado na direção da pesquisa aplicada. Fortemente relacionada está a necessidade de reformar o sistema educacional, que vem falhando na tarefa de estimular a criatividade e a iniciativa, requisitos para que os graduandos enfrentem os desafios atuais. $^{25}$

Outro desafio relaciona-se à reforma da rede de proteção social. No passado, os países asiáticos apostaram no rápido crescimento, acompanhado de uma ampla política educacional, para resolver os problemas sociais. A proteção social era exclusividade das grandes empresas e a maioria das pessoas contava apenas com recursos poupados e com o auxílio de familiares. A crise, com seus fortes impactos,

\footnotetext{
${ }^{23}$ Estes grupos ainda são grandes, muito diversificados e fortemente influenciados pelos acionistas controladores.

${ }^{24}$ A capacidade de atração de capital estrangeiro é baixa, estando relacionada à forte regulamentação que marca muitos setores.

${ }^{25}$ Entre as linhas de ação, aponta-se para modificações na governança das universidades, para a desregulamentação do sistema educacional e para uma maior participação de instituições privadas, estimulando a competição.
} 
deixou nítida a insuficiência dessas práticas. Entretanto, as reformas foram, em geral, tímidas; a Coreia do Sul avançou sobretudo na expansão do sistema de seguro desemprego, embora sua cobertura e o valor dos benefícios continuassem limitados. Enfim, outra direção é avançar na reforma do Estado, tornando-o mais accountable e menos discricionário, descentralizando as decisões e fortalecendo os mecanismos de consulta com a sociedade civil. O fortalecimento da sociedade civil tende a favorecer tanto o monitoramento da ação do Estado como a maior sensibilidade às demandas dos grupos mais vulneráveis.

São estes alguns pontos a desafiar a economia coreana. De um lado, as reformas contribuíram para corrigir as fontes de fragilidade do sistema anterior. Soma-se a isto a presença de bons fundamentos e a existência de grupos empresariais competitivos e de uma burocracia que continua ativa visando fortalecer a indústria. ${ }^{26}$ A estas potencialidades, devem-se acrescentar, todavia, alguns efeitos negativos da crise e das reformas, assim como os novos desafios. Tratam-se de elementos a influenciar as características que o capitalismo coreano irá assumir. Apesar das inúmeras mudanças, é pouco provável que o modelo coreano caminhe na direção de um modelo liberal, pois deve, à semelhança do Japão e da Alemanha, preservar traços de sua organização anterior.

\section{REFERÊNCIAS BIBLIOGRÁFICAS}

AMSDEN, Alice (1989). Asia’s Next Giant: South Korea and Late Industrialization. Oxford: Oxford University Press.

ARESTIS, P., GLICKMAN, M. (2002) "Financial Crisis in Southeast Asia: Dispelling Illusion the Minskyan Way". Cambridge Journal of Economics (26): 232-260.

BRESSER-PEREIRA, L. C., (2001a) "Incompetência e Confidence Building por trás de 20 Anos de Quase Estagnação da América Latina.” Revista de Economia Política 21 (1), janeiro de 2001: 141-166.

BRESSER-PEREIRA, L. C. (2001b) “A Fragilidade que Nasce da Dependência da Poupança Externa”. Valor 1000, setembro de 2001.

CHANG, Ha-Joon. The East Asian Development Experience - the Miracle, the Crisis and the Future. Penang: Third World Network, 2006.

CHUNG, Un-Chan (2004). “The Korean Economy Before and After the Crisis”. In Chung, Duck-Koo e Eichengreen, Barry. The Korean Economy Beyond the Crisis. Cheltenham; Northampton: Edward Elgar, pp. 25-47.

CUMINGS, Bruce (1999). “The Asian Crisis, Democracy, and the End of 'Late' Development." In Pempel, T. J. (ed). The Politics of the Asian Economic Crisis. Ithaca and London: Cornell University Press, pp. 45-61.

EICHENGREEN, Barry e CHUNG, Duck-Koo (2004). “Introduction.” In Chung, Duck-Koo e Eichengreen, Barry. The Korean Economy Beyond the Crisis. Cheltenham; Northampton: Edward Elgar, pp. 1-24.

\footnotetext{
${ }^{26}$ A ação do Estado tem se dado principalmente por meio da formação de parcerias com o setor privado e da oferta de fundos para as atividades de Pesquisa e Desenvolvimento e para setores intensivos em tecnologia (Weiss, 2003, p. 257-258).
} 
EVANS, Peter (2004). Autonomia e Parceria - Estados e Transformação Industrial, Rio de Janeiro, UFRJ.

HAGGARD, Stephen (1990). Pathways from the periphery - the Politics of Growth in the Newly industrialising countries. New York: Cornell University Press.

HAGGARD, Stephen (2000). The Political Economy of the Asian Financial Crisis. Washington, DC: Institute for International Economics.

HALL, Peter (1986). Governing the Economy - The Politics of State Intervention in Britain and France. Cambridge: Polity Press.

GONZALEZ, Lauro (2007) Crises Financeiras Recentes: Revisitando as Experiências da América Latina e da Ásia. São Paulo: Escola de Economia da Fundação Getúlio Vargas, SP, junho de 2007 (Tese de Doutorado).

JOH, Sung Wook (2004). “Corporate Restructuring.” In Chung, Duck-Koo e Eichengreen, Barry. The Korean Economy Beyond the Crisis. Cheltenham; Northampton: Edward Elgar, pp. 194-217.

KOHLI, Atul (2004). State Directed Development: Political Power and Industrialization in the Global Periphery. New York: Cabridge University Press.

KRUGMAN, Paul (1998), “What Happened to Asia?” In http://web.mit.edu/krugman/www/.

LEE, Keun; KIM, Byung-Kook; LEE, Chung e YEE, Jaeyeol (2005). Visible Success and Invisible Failure in Post-Crisis Reform in the Republic of Korea; Interplay of Global Standards, Agents, and Local Specificity. In World Bank Policy Research Working Paper 3651, June 2005.

MINSKY H. P. (1986). Stabilizing an Unstable Economy. New Haven, Yale University Press.

WEISS, Linda (2003). States in the Global Economy - Bringing Domestic Institutions Back In. Cambridge: Cambridge University Press.

WOO-CUMINGS, Meredith (1999). "The State, Democracy, and the Reform of the Corporate Sector in Korea”. In Pempel, T. J. (ed). The Politics of the Asian Economic Crisis. Ithaca and London: Cornell University Press, pp. 116-142.

WORLD BANK (1993). The East Asian Miracle: Economic Growth and Public Policy. New York: Oxford University Press. 